\title{
Common variations within HACEI gene and neuroblastoma susceptibility in a Southern Chinese population
}

This article was published in the following Dove Press journal:

OncoTargets and Therapy

8 February 2017

Number of times this article has been viewed

\author{
Zhuorong Zhang',2,* \\ Ruizhong Zhang ${ }^{1, *}$ \\ Jinhong Zhu ${ }^{3}$ \\ Fenghua Wang' \\ Tianyou Yang' \\ Yan Zou' \\ Jing $\mathrm{He}^{\prime}$ \\ Huimin Xia ${ }^{1,2}$ \\ 'Department of Pediatric Surgery, \\ Guangzhou Institute of Pediatrics, \\ Guangzhou Women and Children's \\ Medical Center, Guangzhou Medical \\ University, ${ }^{2}$ Southern Medical \\ University, Guangzhou, Guangdong, \\ ${ }^{3}$ Molecular Epidemiology Laboratory \\ and Department of Laboratory \\ Medicine, Harbin Medical University \\ Cancer Hospital, Harbin, Heilongjiang, \\ People's Republic of China
}

*These authors contributed equally to this work

\begin{abstract}
Neuroblastoma is a common fatal pediatric cancer of the developing sympathetic nervous system, which accounts for $\sim 10 \%$ of all pediatric cancer deaths. To investigate genetic risk factors related to neuroblastoma, many genome-wide association studies have been performed, and single nucleotide polymorphisms (SNPs) within HACE1 gene have been identified to associate with neuroblastoma risk. However, the association of the HACE1 SNPs with neuroblastoma needs to be validated in Southern Chinese children. We genotyped five SNPs located in the HACE1 gene (rs4336470 C $>$ T, rs9404576 T $>\mathrm{G}$, rs4079063 A $>\mathrm{G}$, rs $2499663 \mathrm{~T}>\mathrm{C}$, and $\mathrm{rs} 2499667 \mathrm{~A}>\mathrm{G}$ ) in 256 Southern Chinese patients in comparison with 531 ethnically matched healthy controls. Single locus analysis showed no significant association between any of HACE1 SNPs and neuroblastoma risk in Southern Chinese children. However, when all the risk genotypes were combined, we found a borderline significant trend toward an increased neuroblastoma risk with 4-5 risk genotypes (adjusted odds ratio $=1.36$, $95 \%$ confidence interval $=0.98-1.89, P=0.065$ ). Moreover, stratified analysis found that carriers of 4-5 risk genotypes tended to develop neuroblastoma in the retroperitoneal region and have more aggressive tumors, progressing to advanced clinical stages III/IV, when compared with those of 0-3 risk genotypes. In conclusion, $H A C E 1$ gene may have weak effect on neuroblastoma risk in Southern Chinese children. Large well-designed studies are needed to strengthen our findings.
\end{abstract}

Keywords: $H A C E 1$, susceptibility, neuroblastoma, GWAS, polymorphism

\section{Introduction}

Neuroblastoma, a severe malignancy of the developing sympathetic nervous system, has been recognized as the most common extracranial solid cancer in infancy, accounting for $\sim 7 \%-10 \%$ of all childhood cancers. ${ }^{1-3}$ Despite advanced therapies and marked improvements in the cure rates for many childhood cancers, the mortality of neuroblastoma remains high. It constitutes $\sim 10 \%$ of all pediatric cancer-related deaths. ${ }^{4,5}$ The incidence rate of neuroblastoma in the live births is $\sim 7.7$ cases per million in China, ${ }^{6}$ which is lower than that in the USA. ${ }^{7}$ Generally, $<40 \%$ of neuroblastoma patients survive $>5$ years after diagnosis. Moreover, survivors are likely to have fewer chances for employment, marriage, and high income because of their chronic health conditions. ${ }^{8}$ Therefore, neuroblastoma has become a great burden and challenge to their families and public health, a situation that warrants further improvement.9,10

Epidemiology studies searching for risk factors failed to identify common environmental exposures that can affect the development of neuroblastoma. ${ }^{11,12}$ However, accumulating evidence from genome-wide association studies (GWASs) suggests
Correspondence: Huimin Xia; Jing He Department of Pediatric Surgery, Guangzhou Institute of Pediatrics, Guangzhou Women and Children's Medical Center, Guangzhou Medical University, 9 Jinsui Road, Guangzhou, Guangdong 510623, People's Republic of China

Tel +86203807600 I; +86203807 6560 Fax +86 203807 6020; +862038076560 Email xia-huimin@foxmail.com; hejing198374@gmail.com hy
hereby accept the Terms. Non-commercial uses of the work are permitted without any further permission from Dove Medical Press Limited, provided the work is properly attributed. For permission for commercial use of this work, please see paragraphs 4.2 and 5 of our Terms (https://www.dovepress.com/terms.php). 
that genetic factors are able to modify neuroblastoma susceptibility. ${ }^{13,14}$ A recent GWAS by Diskin et $\mathrm{al}^{15}$ has demonstrated that several loci are associated with neuroblastoma susceptibility and disease progression, such as loci within the HACE1 (encoding HECT domain- and ankyrin repeat-containing $\mathrm{E} 3$ ubiquitin protein ligase 1) and $L I N 28 B$ (encoding lin28 homolog B) genes. In that study, 2,817 neuroblastoma cases and 7,473 controls were enrolled, and low HACE1 expression was observed to be significantly associated with worse overall survival in newly diagnosed neuroblastoma patients, suggesting $H A C E 1$ at chromosome $6 q 16$ as a tumor suppressor gene. In addition, the authors identified five single nucleotide polymorphisms (SNPs) (rs4336470 $\mathrm{C}>\mathrm{T}$, rs9404576 $\mathrm{T}>\mathrm{G}, \mathrm{rs} 4079063 \mathrm{~A}>\mathrm{G}$, rs2499663 $\mathrm{T}>\mathrm{C}$, and $\mathrm{rs} 2499667 \mathrm{~A}>\mathrm{G}$ ) within the HACE1 gene that may contribute independently to neuroblastoma risk. To date, the association between neuroblastoma susceptibility and these SNPs has been validated in the European ancestry, African-Americans, and Italian population ${ }^{15,16}$ but not yet in Asians.

To corroborate and comprehensively evaluate the impact of the GWAS-identified HACE1 gene polymorphisms on neuroblastoma risk, these five SNPs were analyzed in a Southern Chinese population with 256 neuroblastoma cases and 531 cancer-free controls.

\section{Subjects and methods Study subjects}

A total of 256 histopathologically confirmed primary neuroblastoma cases and 531 cancer-free controls were included in this study, as we had described in detail previously. ${ }^{10,17-20}$ Briefly, all the 256 neuroblastoma cases were newly diagnosed and histopathologically confirmed patients without metastasis from other organs. The cases were genetically unrelated ethnic Han Chinese children who received treatments at the Department of Pediatric Surgery, Guangzhou Women and Children's Medical Center, mainly between February 2010 and November 2015, while age-, gender-, and race-matched controls were randomly recruited from children undergoing routine physical examination at the same hospital during the same period. The parents or guardians of the children provided informed consent for the children's participation in this study. This study was approved by the Ethics Committee of Guangzhou Women and Children's Medical Center.

\section{Genotyping}

Genotyping for the five GWAS-identified polymorphisms $(\mathrm{rs} 4336470 \mathrm{C}>\mathrm{T}, \mathrm{rs} 9404576 \mathrm{~T}>\mathrm{G}, \mathrm{rs} 4079063 \mathrm{~A}>\mathrm{G}$, rs2499663 $\mathrm{T}>\mathrm{C}$, and rs2499667 $\mathrm{A}>\mathrm{G})^{15}$ was performed in a 384-well plate using TaqMan Real-Time PCR method using the typical 7900 HT sequence detector system (Applied Biosystems, Foster City, CA, USA) as described previously. ${ }^{21,22}$ Approximately $10 \%$ of the samples were randomly selected and regenotyped to validate the accuracy of genotyping results from TaqMan Real-Time PCR. The results were $100 \%$ concordant.

\section{Statistical analysis}

The chi-square test was performed to examine the differences in the demographics and frequency distributions of genotypes between cases and controls. Unconditional multivariate logistic regression analysis was performed and adjusted for age and gender. The strength of associations between these five polymorphisms and neuroblastoma risk was estimated using odds ratios (ORs) and 95\% confidence intervals (CIs). Stratified analysis was performed by age, gender, tumor sites, and clinical stages. $P$-values $<0.05$ were considered as statistically significant. All statistical analyses were two-sided and performed using the SAS software (version 9.1; SAS Institute, Cary, NC, USA).

\section{Results}

\section{Population characteristics}

The distributions of the demographic characteristics of the cases and controls are summarized in Table S1. No statistically significant difference was observed between cases and controls regarding age $(P=0.239)$ and gender $(P=0.333)$. According to International Neuroblastoma Staging System criteria, ${ }^{23} 54$ (21.09\%), 65 (25.39\%), 44 (17.19\%), 77 (30.08\%), and $9(3.52 \%)$ patients had clinical stage I, II, III, IV, and $4 \mathrm{~s}$ neuroblastomas, respectively. In terms of tumor sites, the neuroblastoma mainly occurred in adrenal glands $(n=46$, $17.97 \%)$, retroperitoneal regions $(n=87,33.98 \%)$, mediastinum $(n=90,35.16 \%)$, and other regions $(n=25,9.77 \%)$.

\section{Associations of selected HACEI gene SNPs with neuroblastoma susceptibility}

The genotype frequencies of the five selected SNPs and their associations with the risk of neuroblastoma are shown in Table 1. Of the included participants, 249 cases and 530 controls were successfully genotyped. Overall, the association between individual polymorphisms and neuroblastoma susceptibility did not reach statistical significance. We found that the rs $4336470 \mathrm{~T}$, rs $9404576 \mathrm{G}, \mathrm{rs} 4079063 \mathrm{~A}$, rs2499663 T, and rs2499667 A allele carriers were associated with an increased neuroblastoma risk. When the risk genotypes were combined, we observed a borderline increased 
Table I Logistic regression analysis of associations of HACEI gene polymorphisms with neuroblastoma susceptibility

\begin{tabular}{|c|c|c|c|c|c|c|c|}
\hline Genotypes & $\begin{array}{l}\text { Cases }(n=249), \\
\text { No. }(\%)\end{array}$ & $\begin{array}{l}\text { Controls }(n=530) \text {, } \\
\text { No. }(\%)\end{array}$ & $P$-value ${ }^{a}$ & $\begin{array}{l}\text { Crude OR } \\
(95 \% \mathrm{Cl})\end{array}$ & $P$-value & $\begin{array}{l}\text { Adjusted OR } \\
(95 \% \mathrm{Cl})^{\mathrm{b}}\end{array}$ & $P$-value ${ }^{b}$ \\
\hline \multicolumn{8}{|l|}{ rs4336470 C > T } \\
\hline $\mathrm{CC}$ & $130(52.21)$ & $303(57.17)$ & & 1.00 & & 1.00 & \\
\hline $\mathrm{CT}$ & 99 (39.76) & I 88 (35.47) & & $1.23(0.89-1.69)$ & 0.207 & $1.22(0.89-1.68)$ & 0.220 \\
\hline TT & $20(8.03)$ & $39(7.36)$ & & $1.20(0.67-2.13)$ & 0.545 & $1.22(0.68-2.18)$ & 0.500 \\
\hline Dominant & $119(47.79)$ & $227(42.83)$ & 0.194 & $1.22(0.90-1.65)$ & 0.194 & $1.22(0.90-1.65)$ & 0.197 \\
\hline Additive model & & & 0.429 & $1.15(0.91-1.45)$ & 0.247 & $1.15(0.91-1.46)$ & 0.236 \\
\hline Recessive & 229 (91.97) & 491 (92.64) & 0.742 & $1.10(0.63-1.93)$ & 0.740 & $1.13(0.64-1.98)$ & 0.681 \\
\hline \multicolumn{8}{|l|}{ rs9404576 T>G } \\
\hline $\mathrm{TT}$ & I 34 (53.82) & $303(57.17)$ & & 1.00 & & 1.00 & \\
\hline TG & 97 (38.96) & $189(35.66)$ & & $1.16(0.84-1.60)$ & 0.359 & $1.16(0.84-1.59)$ & 0.373 \\
\hline GG & $18(7.23)$ & $38(7.17)$ & & $1.07(0.59-1.95)$ & 0.822 & $1.09(0.60-1.99)$ & 0.774 \\
\hline Dominant & $115(46.18)$ & $227(42.83)$ & 0.379 & $1.15(0.85-1.55)$ & 0.379 & $1.15(0.85-1.55)$ & 0.380 \\
\hline Additive model & & & 0.657 & $1.09(0.86-1.38)$ & 0.479 & $1.09(0.86-1.39)$ & 0.462 \\
\hline Recessive & 231 (92.77) & $492(92.83)$ & 0.976 & $1.01(0.56-1.81)$ & 0.976 & $1.03(0.57-1.85)$ & 0.921 \\
\hline \multicolumn{8}{|l|}{$r s 4079063 A>G$} \\
\hline $\mathrm{AA}$ & $92(36.95)$ & 189 (35.66) & & 1.00 & & 1.00 & \\
\hline$A G$ & 116 (46.59) & $242(45.66)$ & & $0.99(0.7 \mid-1.37)$ & 0.928 & $0.98(0.70-1.36)$ & 0.880 \\
\hline GG & $4 I(16.47)$ & 99 (18.68) & & $0.85(0.55-1.32)$ & 0.472 & $0.85(0.55-1.32)$ & 0.469 \\
\hline Dominant & $157(63.05)$ & $34 I(64.34)$ & 0.727 & $0.95(0.69-1.29)$ & 0.726 & $0.94(0.69-1.28)$ & 0.690 \\
\hline Additive model & & & 0.749 & $0.93(0.76-1.15)$ & 0.523 & $0.93(0.75-1.15)$ & 0.509 \\
\hline Recessive & $208(83.53)$ & $43 I(81.32)$ & 0.450 & $0.86(0.58-1.28)$ & 0.453 & $0.86(0.58-1.29)$ & 0.466 \\
\hline \multicolumn{8}{|l|}{$r s 2499663 \mathrm{~T}>\mathrm{C}$} \\
\hline $\mathrm{TT}$ & $93(37.35)$ & $189(35.66)$ & & 1.00 & & 1.00 & \\
\hline $\mathrm{TC}$ & $115(46.18)$ & $243(45.85)$ & & $0.96(0.69-1.34)$ & 0.819 & $0.95(0.68-1.33)$ & 0.773 \\
\hline $\mathrm{CC}$ & $4 \mid(16.47)$ & $98(18.49)$ & & $0.85(0.55-1.32)$ & $0.47 \mid$ & $0.85(0.55-1.32)$ & 0.470 \\
\hline Dominant & $156(62.65)$ & 341 (64.34) & 0.648 & $0.93(0.68-1.27)$ & 0.647 & $0.92(0.68-1.26)$ & 0.614 \\
\hline Additive model & & & 0.767 & $0.93(0.75-1.15)$ & 0.497 & $0.93(0.75-1.15)$ & 0.486 \\
\hline Recessive & $208(83.53)$ & $432(8 I .5 I)$ & 0.489 & $0.87(0.58-1.30)$ & 0.675 & $0.87(0.59-1.30)$ & 0.508 \\
\hline \multicolumn{8}{|l|}{$r s 2499667 \mathrm{~A}>\mathrm{G}$} \\
\hline AA & $90(36.14)$ & $18 \mid(34.15)$ & & 1.00 & & 1.00 & \\
\hline AG & II 8 (47.39) & 248 (46.79) & & $0.96(0.69-1.34)$ & 0.796 & $0.95(0.68-1.32)$ & 0.744 \\
\hline GG & $4 \mathrm{I}(16.47)$ & 101 (19.06) & & $0.82(0.53-1.27)$ & 0.369 & $0.81(0.52-1.27)$ & 0.362 \\
\hline Dominant & $159(63.86)$ & $349(65.85)$ & 0.587 & $0.92(0.67-1.26)$ & 0.586 & $0.91(0.66-1.24)$ & 0.546 \\
\hline Additive model & & & 0.657 & $0.91(0.74-1.13)$ & 0.400 & $0.91(0.73-1.13)$ & 0.384 \\
\hline Recessive & $208(83.53)$ & $429(80.94)$ & 0.379 & $0.84(0.56-1.25)$ & 0.383 & $0.84(0.56-1.25)$ & 0.394 \\
\hline \multicolumn{8}{|l|}{ Risk genotypes } \\
\hline $0-3$ & 167 (67.07) & 390 (73.58) & & 1.00 & & 1.00 & \\
\hline $4-5$ & $82(32.93)$ & $140(26.42)$ & 0.062 & $1.37(0.99-1.90)$ & $0.06 \mathrm{I}$ & $1.36(0.98-1.89)$ & 0.065 \\
\hline
\end{tabular}

Notes: a Chi-square test for genotype distributions between cases and controls. ${ }^{b}$ Adjusted for age and gender.

Abbreviations: $\mathrm{Cl}$, confidence interval; $\mathrm{OR}$, odds ratio.

neuroblastoma risk for the subjects carrying 4-5 risk genotypes (adjusted $\mathrm{OR}=1.36,95 \% \mathrm{CI}=0.98-1.89, P=0.065$ ) when compared with those carrying $0-3$ risk genotypes.

\section{Stratified analysis of selected polymorphisms and neuroblastoma susceptibility}

We performed stratification analysis on rs $4336470 \mathrm{C}>\mathrm{T}$ and rs9404576 T $>\mathrm{G}$ to estimate the effects of variant genotypes with neuroblastoma susceptibility. The cumulative effects of the five risk genotypes were also determined (Table 2). Similarly, as described earlier, no significant association was obtained in our study. However, a comparison of 0-3 combined risk genotypes and 4-5 combined risk genotypes indicated that $4-5$ combined risk genotypes had a trend to increase the risk of clinical stages III/IV neuroblastoma (adjusted $\mathrm{OR}=1.51,95 \% \mathrm{CI}=0.98-2.31, P=0.060$ ) and the risk of tumor in retroperitoneal region (adjusted $\mathrm{OR}=1.55$, $95 \% \mathrm{CI}=0.94-2.54, P=0.083$ ).

\section{Discussion}

The HACE1 gene encodes an E3 ubiquitin protein ligase, which was first identified in human Wilms' tumor and further observed to be silenced in the majority of Wilms' tumors via hypermethylation. ${ }^{24}$ Similarly, a marked reduction in $H A C E 1$ gene expression or even epigenetic silencing caused 


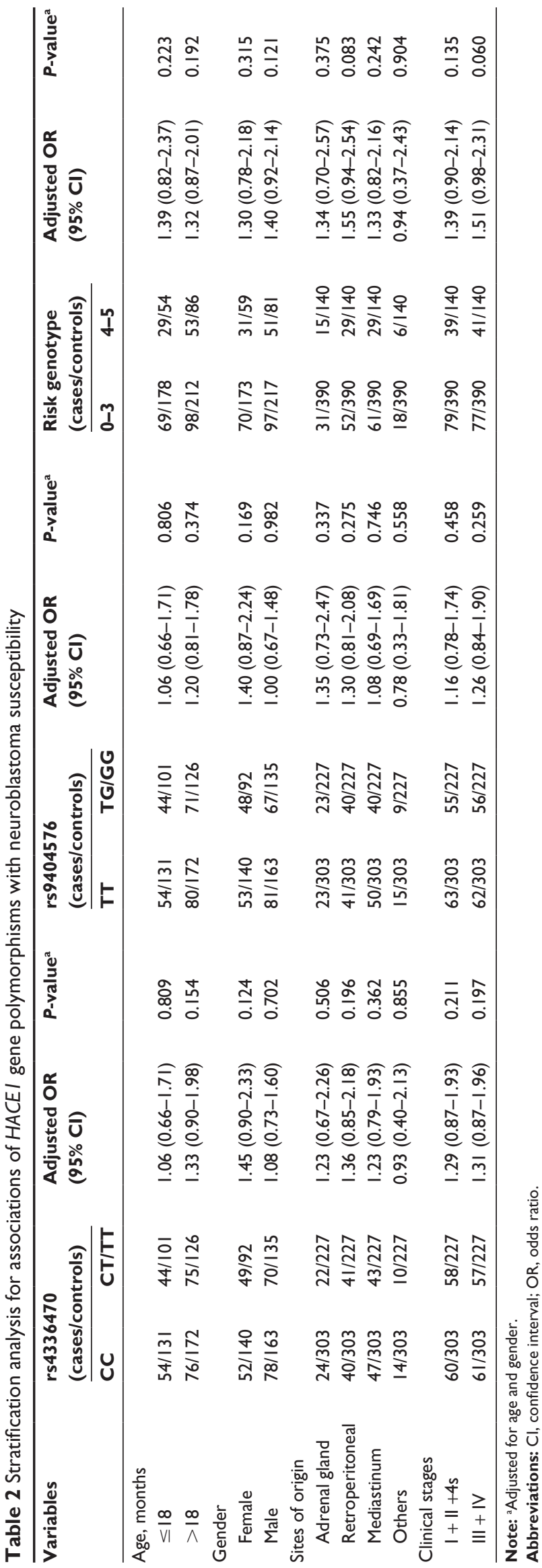

by methylation has been reported in colorectal carcinoma, gastric cancer, breast malignancy, and nasal-type extranodal NK/T-cell lymphoma. ${ }^{25-28}$ HACE1 depletion enhances cell migration independently of growth factor stimulation, which may promote malignant conversion. HACE1 inhibits cell migration by degrading small GTPase Rac1 (a key regulator of cell motility) ${ }^{29}$ and suppresses cell growth through its E3 ubiquitin ligase function. Downregulation of HACE1 is a common event in multiple human tumors. HACE1 inactivation in mice leads to the development of cancer, a process that is accelerated with the addition of "second hits" such as mutations in $\mathrm{p} 53 .{ }^{30}$ Moreover, HACE1 inhibits cell cycle progression and regulates ligand-activated transcription by regulating cyclin D1 degradation ${ }^{30}$ and retinoic acid receptor (RAR) activity, ${ }^{31}$ respectively. Taken together, HACE1 is considered as a putative tumor suppressor. HACE1 deficiency or downregulation may increase the susceptibility to additional genetic or environmental cancer triggers.

To the best of our knowledge, all of the GWASs on neuroblastoma have been performed in European American populations. In fact, European Americans form a structured population due to historical immigration of diverse source populations. Therefore, with an aim to prevent false-positive associations resulting from population stratification, it is necessary to discern the ancestry of European Americans who were genotyped in the association studies. ${ }^{32}$ Some significantly associated SNPs have been replicated in North European sample from the UK, ${ }^{33}$ African Americans, ${ }^{34}$ and Italian population. ${ }^{15,16}$ Based on these observations, it is obvious that confirmatory studies are needed to validate the former GWAS findings in different populations and ethnicities. ${ }^{16}$

In order to validate the association between $H A C E 1$ polymorphisms and neuroblastoma susceptibility in Southern Chinese population, we conducted the current hospital-based case-control study. Unexpectedly, the association between these five polymorphisms and neuroblastoma susceptibility did not reach statistical significance. Only when the risk genotypes were combined, we observed a borderline significantly increased neuroblastoma risk among subjects carrying $4-5$ risk genotypes versus those carrying 0-3 risk genotypes. Similarly, no significant difference was obtained in the stratified analysis. However, we found that 4-5 combined risk genotypes tended to increase the risk of developing clinical stages III/IV neuroblastoma and tumor in retroperitoneal region. Diskin et al ${ }^{15}$ report that the rs4336470 C, rs9404576 T, rs4079063 A, rs2499663 T, and rs2499667 A allele carriers may confer risk to develop 
neuroblastoma. Thus, in the current study, we found that the rs4336470 T rs9404576 G, rs4079063 A, rs2499663 T, and rs2499667 A allele carriers were associated with an increased neuroblastoma risk. The rs4079063 A, rs2499663 T, and rs2499667 A allele carriers have a similar trend with the Diskin's study. Thus, the rest two have an opposite effect. This may be ascribed to the limited sample size as well as the ethnicity difference.

Although this is the first study to estimate the association between these five SNPs in HACE1 gene and neuroblastoma susceptibility in Southern Chinese children, several limitations should be addressed. First, because of the nature of retrospective study design, information and selection bias could not be completely avoided. We could only reduce these biases through performing frequency matching of neuroblastoma cases and controls by age and gender, to some extent, since information on living environment, dietary intake, and paternal exposures was not available. Second, only five most significant polymorphisms reported previously elsewhere ${ }^{15}$ are included in the present study. More polymorphisms, especially the potentially functional SNPs not contained in GWASs, remained to be discovered and replicated. Finally, although this is the largest study in Southern Chinese population, there are only 256 neuroblastoma patients and 531 cancer-free controls enrolled. The sample size is relatively small, which may have limited the statistical power.

\section{Conclusion}

Our results suggested that these five SNPs within HACE1 gene were not associated with neuroblastoma susceptibility in the Southern Chinese population, but several trends of combined risk genotypes should be mentioned. Our study highlights genetic heterogeneity in neuroblastoma susceptibility in different populations. In the future, welldesigned prospective studies with larger sample size and more homogeneous samples should be performed to confirm our findings.

\section{Acknowledgments}

This study was supported by the grant of State Clinical Key Specialty Construction Project (Pediatric Surgery) 2013 (no GJLCZD1301) and the grant of Clinical Medicine Research and Transformation Center of Brain Injury in Premature Infant in Guangzhou (no 520101-2150092). We thank Yanlu Tong, Hongjiao Chen, and Hezhen Wang for their assistance in DNA extraction and medical histories information collection.

\section{Disclosure}

The authors report no conflicts of interest in this work.

\section{References}

1. Maris JM, Mosse YP, Bradfield JP, et al. Chromosome 6p22 locus associated with clinically aggressive neuroblastoma. $N$ Engl J Med. 2008; 358(24):2585-2593.

2. Smith MA, Seibel NL, Altekruse SF, et al. Outcomes for children and adolescents with cancer: challenges for the twenty-first century. J Clin Oncol. 2010;28(15):2625-2634.

3. Han W, Zhou Y, Zhong R, et al. Functional polymorphisms in FAS/ FASL system increase the risk of neuroblastoma in Chinese population. PLoS One. 2013;8(8):e71656.

4. Oldridge DA, Wood AC, Weichert-Leahey N, et al. Genetic predisposition to neuroblastoma mediated by a LMO1 super-enhancer polymorphism. Nature. 2015;528(7582):418-421.

5. Maris JM, Hogarty MD, Bagatell R, Cohn SL. Neuroblastoma. Lancet. 2007;369(9579):2106-2120.

6. Bao PP, Li K, Wu CX, et al. [Recent incidences and trends of childhood malignant solid tumors in Shanghai, 2002-2010]. Zhonghua Er Ke Za Zhi. 2013;51(4):288-294. Chinese.

7. Gurney JG, Ross JA, Wall DA, Bleyer WA, Severson RK, Robison LL. Infant cancer in the U.S.: histology-specific incidence and trends, 1973 to 1992. J Pediatr Hematol Oncol. 1997;19(5):428-432.

8. Laverdiere C, Liu Q, Yasui Y, et al. Long-term outcomes in survivors of neuroblastoma: a report from the Childhood Cancer Survivor Study. J Natl Cancer Inst. 2009;101(16):1131-1140.

9. Kaatsch P. Epidemiology of childhood cancer. Cancer Treat Rev. 2010;36(4):277-285.

10. He J, Yang T, Zhang R, et al. Potentially functional polymorphisms in the LIN28B gene contribute to neuroblastoma susceptibility in Chinese children. J Cell Mol Med. 2016;20(8):1534-1541.

11. De Roos AJ, Olshan AF, Teschke K, et al. Parental occupational exposures to chemicals and incidence of neuroblastoma in offspring. Am J Epidemiol. 2001;154(2):106-114.

12. De Roos AJ, Teschke K, Savitz DA, et al. Parental occupational exposures to electromagnetic fields and radiation and the incidence of neuroblastoma in offspring. Epidemiology. 2001;12(5):508-517.

13. Diskin SJ, Capasso M, Diamond M, et al. Rare variants in TP53 and susceptibility to neuroblastoma. J Natl Cancer Inst. 2014;106(4):dju047.

14. Capasso M, Diskin S, Cimmino F, et al. Common genetic variants in NEFL influence gene expression and neuroblastoma risk. Cancer Res. 2014;74(23):6913-6924.

15. Diskin SJ, Capasso M, Schnepp RW, et al. Common variation at $6 \mathrm{q} 16$ within HACE1 and LIN28B influences susceptibility to neuroblastoma. Nat Genet. 2012;44(10):1126-1130.

16. Capasso M, Diskin SJ, Totaro F, et al. Replication of GWAS-identified neuroblastoma risk loci strengthens the role of BARD1 and affirms the cumulative effect of genetic variations on disease susceptibility. Carcinogenesis. 2013;34(3):605-611.

17. He J, Zhang R, Zou Y, et al. Evaluation of GWAS-identified SNPs at 6 p22 with neuroblastoma susceptibility in a Chinese population. Tumour Biol. 2016;37(2):1635-1639.

18. He J, Wang F, Zhu J, et al. Association of potentially functional variants in the XPG gene with neuroblastoma risk in a Chinese population. J Cell Mol Med. 2016;20(8):1481-1490.

19. He J, Zhong W, Zeng J, et al. LMO1 gene polymorphisms contribute to decreased neuroblastoma susceptibility in a Southern Chinese population. Oncotarget. 2016;7(16):22770-22778.

20. Zheng J, Zhang R, Zhu J, et al. Lack of associations between XPC gene polymorphisms and neuroblastoma susceptibility in a Chinese population. Biomed Res Int. 2016;2016:2932049.

21. He J, Qiu LX, Wang MY, et al. Polymorphisms in the XPG gene and risk of gastric cancer in Chinese populations. Hum Genet. 2012;131(7): $1235-1244$. 
22. He J, Wang MY, Qiu LX, et al. Genetic variations of mTORC1 genes and risk of gastric cancer in an Eastern Chinese population. Mol Carcinog. 2013;52(suppl 1):E70-E79.

23. Brodeur GM, Pritchard J, Berthold F, et al. Revisions of the international criteria for neuroblastoma diagnosis, staging, and response to treatment. J Clin Oncol. 1993;11(8):1466-1477.

24. Anglesio MS, Evdokimova V, Melnyk N, et al. Differential expression of a novel ankyrin containing E3 ubiquitin-protein ligase, Hace1, in sporadic Wilms' tumor versus normal kidney. Hum Mol Genet. 2004; 13(18):2061-2074.

25. Huang Y, de Reynies A, de Leval L, et al. Gene expression profiling identifies emerging oncogenic pathways operating in extranodal NK/ T-cell lymphoma, nasal type. Blood. 2010;115(6):1226-1237.

26. Hibi K, Sakata M, Sakuraba K, et al. Aberrant methylation of the HACE1 gene is frequently detected in advanced colorectal cancer. Anticancer Res. 2008;28(3A):1581-1584.

27. Sakata M, Kitamura YH, Sakuraba K, et al. Methylation of HACE1 in gastric carcinoma. Anticancer Res. 2009;29(6):2231-2233.

28. Goka ET, Lippman ME. Loss of the E3 ubiquitin ligase HACE1 results in enhanced Rac1 signaling contributing to breast cancer progression. Oncogene. 2015;34(42):5395-5405.
29. Castillo-Lluva S, Tan CT, Daugaard M, Sorensen PH, Malliri A. The tumour suppressor HACE1 controls cell migration by regulating Rac1 degradation. Oncogene. 2013;32(13):1735-1742.

30. Zhang L, Anglesio MS, O'Sullivan M, et al. The E3 ligase HACE1 is a critical chromosome 6q21 tumor suppressor involved in multiple cancers. Nat Med. 2007;13(9):1060-1069.

31. Zhao J, Zhang Z, Vucetic Z, Soprano KJ, Soprano DR. HACE1: a novel repressor of RAR transcriptional activity. J Cell Biochem. 2009; 107(3):482-493.

32. Price AL, Butler J, Patterson N, et al. Discerning the ancestry of European Americans in genetic association studies. PLoS Genet. 2008; 4(1):e236

33. Capasso M, Devoto M, Hou C, et al. Common variations in BARD1 influence susceptibility to high-risk neuroblastoma. Nat Genet. 2009; 41(6):718-723.

34. Latorre V, Diskin SJ, Diamond MA, et al. Replication of neuroblastoma SNP association at the BARD1 locus in African-Americans. Cancer Epidemiol Biomarkers Prev. 2012;21(4):658-663. 


\section{Supplementary material}

Table SI Characteristics of neuroblastoma cases and cancerfree controls

\begin{tabular}{|c|c|c|c|c|c|}
\hline \multirow[t]{2}{*}{ Variables } & \multicolumn{2}{|c|}{$\begin{array}{l}\text { Cases } \\
(n=256)\end{array}$} & \multicolumn{2}{|c|}{$\begin{array}{l}\text { Controls } \\
(n=531)\end{array}$} & \multirow[t]{2}{*}{$P$-value ${ }^{a}$} \\
\hline & $\mathbf{n}$ & $\%$ & $\mathbf{n}$ & $\%$ & \\
\hline Age range, months & \multicolumn{2}{|c|}{$0-156$} & \multicolumn{2}{|c|}{$0.07-156$} & 0.239 \\
\hline$\leq 18$ & 101 & 39.45 & 233 & 43.88 & \\
\hline$>18$ & 155 & 60.55 & 298 & 56.12 & \\
\hline Mean \pm SD & \multicolumn{2}{|c|}{$30.87 \pm 26.45$} & \multicolumn{2}{|c|}{$29.73 \pm 24.86$} & \\
\hline \multicolumn{6}{|l|}{ Gender } \\
\hline Female & 103 & 40.23 & 233 & 43.88 & 0.333 \\
\hline Male & 153 & 59.77 & 298 & 56.12 & \\
\hline \multicolumn{6}{|l|}{ Clinical stages } \\
\hline I & 54 & 21.09 & & & \\
\hline ॥ & 65 & 25.39 & & & \\
\hline III & 44 & 17.19 & & & \\
\hline IV & 77 & 30.08 & & & \\
\hline $4 s$ & 9 & 3.52 & & & \\
\hline NA & 7 & 2.73 & & & \\
\hline \multicolumn{6}{|l|}{ Sites of origin } \\
\hline Adrenal gland & 46 & 17.97 & & & \\
\hline Retroperitoneal region & 87 & 33.98 & & & \\
\hline Mediastinum & 90 & 35.16 & & & \\
\hline Other regions & 25 & 9.77 & & & \\
\hline NA & 8 & 3.13 & & & \\
\hline
\end{tabular}

Note: ${ }^{a}$ Two-sided $\chi^{2}$ test for distributions between neuroblastoma cases and controls.

Abbreviation: NA, not available.

\section{Publish your work in this journal}

OncoTargets and Therapy is an international, peer-reviewed, open access journal focusing on the pathological basis of all cancers, potential targets for therapy and treatment protocols employed to improve the management of cancer patients. The journal also focuses on the impact of management programs and new therapeutic agents and protocols on

\section{Dovepress}

patient perspectives such as quality of life, adherence and satisfaction. The manuscript management system is completely online and includes a very quick and fair peer-review system, which is all easy to use. Visit http://www.dovepress.com/testimonials.php to read real quotes from published authors. 